\title{
INVESTIGATION OF INTERCRITICAL HEAT TREATMENT TEMPERATURE EFFECT ON MICROSTRUCTURE AND MECHANICAL PROPERTIES OF DUAL PHASE (DP) STEEL
}

\author{
Mohammad Davari, Mehdi Mansouri ${ }^{*}$ \\ Advanced Materials Research Center, Department of Materials Engineering, \\ Najafabad Branch, Islamic Azad University, Najafabad, Iran
}

Received 05.06.2017

Accepted 29.06.2017

\begin{abstract}
In the present study, the effect of intercritical heat treatment temperature on the tensile properties and work hardening behavior of ferritic-martensitic dual-phase steel have been investigated utilizing tensile test, microhardness measurement and microscopic observation. Plain carbon steel sheet with a thickness of $2 \mathrm{~mm}$ was heat treated at $760,780,800,820$ and $840{ }^{\circ} \mathrm{C}$ intercritical temperatures. The results showed that martensite volume fraction $\left(\mathrm{V}_{\mathrm{m}}\right)$ increases from 32 to $81 \%$ with increasing temperature from 760 to $840{ }^{\circ} \mathrm{C}$. The mechanical properties of samples were examined by tensile and microhardness tests. The results revealed that yield strength was increased linearly with the increase in $\mathrm{V}_{\mathrm{m}}$, but the ultimate strength was increased up to $55 \% \mathrm{~V}_{\mathrm{m}}$ and then decreased afterward. Analyzing the work hardening behavior in term of Hollomon equation showed that in samples with less than $55 \% \mathrm{~V}_{\mathrm{m}}$, the work hardening took place in one stage and the work hardening exponent increased with increasing $\mathrm{V}_{\mathrm{m}}$. More than one stage was observed in the work hardening behavior when $\mathrm{V}_{\mathrm{m}}$ was increased. The results of microhardness test showed that microhardness of the martensite is decreased by increase in heat treatment temperature while the ferrite microhardness is nearly constant for all heat-treated samples.
\end{abstract}

Key words: Dual phase steel; Microstructure; Intercritical heat treatment; Mechanical Characterization.

\section{Introduction}

Due to fuel price increasing in 1970s, vehicle manufacturers tended to use lighter materials in vehicle structures to reduce the vehicle weight and consequently fuel consumption and environment pollutants [1]. Results have shown that $1 \%$ reduction in vehicle weight can reduce fuel consumption by 0.6 to $1 \%$ [2]. On the other side, the

* Corresponding author: Mehdi Mansouri,MMansouri@pmt.iaun.ac.ir 
vehicle weight reduction should not decrease the safety of occupants. The simultaneous need to reduce the fuel consumption and increase the occupant safety leads to achieve new generations of advanced high-strength steels such as dual-phase (DP) steels [3-9]. Dual-phase steels' microstructure consists of hard martensite islands which are distributed in the soft ferrite matrix. DP steels have unique properties such as low elastic limit, high initial work hardening rate, continuous yield, high tensile strength and favorably uniform elongation [10]. In recent years, due to the immense importance of these types of steels in replacement with conventional steels used in the automotive industry, extensive research has been performed on microstructural and mechanical properties of DP steels and improvement of these properties [8, 11]. The results of these researches have shown that several parameters such as the formed phases fraction, the carbon content of raw steel, intercritical heat treatment temperature and many other parameters influence the properties of DP steels. By investigating the thermomechanical parameters in intercritical area on tensile properties of dual-phase steels, Ahmad et al. [12] showed that with increasing intercritical annealing temperature, martensite volume fraction $\left(\mathrm{V}_{\mathrm{m}}\right)$ is increased causing increase in tensile strength. Fallahi et al. [13] studied the microstructural parameters of DP steels. Their results showed that the optimum tensile properties and the impact resistance are achievable by a ferritic-martensitic structure with an average size of $4 \mu \mathrm{m}$ for ferrite and with 35 to $40 \% \mathrm{~V}_{\mathrm{m}}$. On the other hand, the results of Bag et al. [14] showed that the optimum combination of high strength and ductility has been achieved in equal volume fraction of ferrite and martensite. The results have indicated that the strength of martensite influences the tensile strength of DP steels, which is increased non-linearly by increasing strength of formed martensite [15]. As reviewed, the properties of DP steels are dependent strongly on steel composition and intercritical heat treatment parameters.

Because there are few results on the effects of heat treatment temperature on mechanical behavior of DP steels, the aim of this study is to investigate the effect of heat treatment temperature on tensile properties and work-hardening behavior of DP steels.

\section{Materials and Methods}

Plain carbon steel sheet with $2 \mathrm{~mm}$ thickness was used as the starting material. The chemical composition of used steel is presented in Table 1 .

Table 1. The chemical composition of plain carbon steel used in this study

\begin{tabular}{llllllllll}
\hline Element & $\mathrm{C}$ & $\mathrm{Mn}$ & $\mathrm{S}$ & $\mathrm{Si}$ & $\mathrm{P}$ & $\mathrm{Al}$ & $\mathrm{Cr}$ & $\mathrm{Mo}$ & $\mathrm{Ni}$ \\
\hline Wt. \% & 0.2 & 0.54 & 0.024 & 0.3 & 0.025 & 0.02 & 0.3 & 0.007 & 0.3 \\
\hline
\end{tabular}


Intercritical temperatures, i.e. $\mathrm{A}_{1}$ and $\mathrm{A}_{3}$, for the as-received steel were determined utilizing equations 1 and 2 [16]. The $A_{1}$ and $A_{3}$ intercritical temperatures were 738 and $852{ }^{\circ} \mathrm{C}$, respectively.

$$
A_{l}=751-16.3 C-27.5 \mathrm{Mn}-5.5 \mathrm{Cu}-15.9 \mathrm{Ni}+34.9 \mathrm{Si}+12.7 \mathrm{Cr}+3.7 \mathrm{Mo}
$$

Based on determined intercritical temperatures heat treatment was performed at various temperatures, i.e. $760,780,800,820$ and $840{ }^{\circ} \mathrm{C}$. Heat treatments of samples were done in a muffle furnace for $20 \mathrm{~min}$. The samples were quenched in $5 \%$ brine solution immediately after the heat treatment.

Metallographic samples were prepared according to standard metallographic grinding and polishing methods for both as-received and heat-treated samples. The cross-sections of samples were etched by $2 \%$ Nital solution. Structural examinations were carried out by optical microscope. The martensite volume fraction of samples was determined utilizing the point counting method according to ASTM E 562. Tensile tests samples with $50 \mathrm{~mm}$ gauge length and $200 \mathrm{~mm}$ overall length were machined according to the ASTM E8M for as-received and heat-treated samples. Tensile tests were conducted at room temperature by Instron testing machine with $10 \mathrm{~mm} / \mathrm{min}$ speed. The failure energy (FE) was calculated by measuring the area under stress-strain curve up to the final failure points utilizing equation 3 according to the Riemann Sums concept [17]:

$$
\text { Failure energy }=\sum_{i=1}^{i=n} \sigma(i)[\varepsilon(i)-\varepsilon(i-1)]
$$

where $\sigma$ is stress, $\varepsilon$ the strain, $i$ the sampled data and $n$ the fracture stress. $25 \mathrm{gf}$.

Microhardness measurement was conducted using loads ranging between 10 and

\section{Results and discussion}

Fig. 1a shows the optical image of the as-received sample. As shown the microstructure of this sample consists of ferrite and small amount of pearlite. The obtained microstructure after intercritical heat treatment at $760{ }^{\circ} \mathrm{C}$ and brain quenching, shows enclosed $32 \%$ volume of martensite islands in almost continuous ferritic matrix (Fig.1b). Further increase in intercritical temperature results to higher martensite volume fraction(Fig.1b-f). 

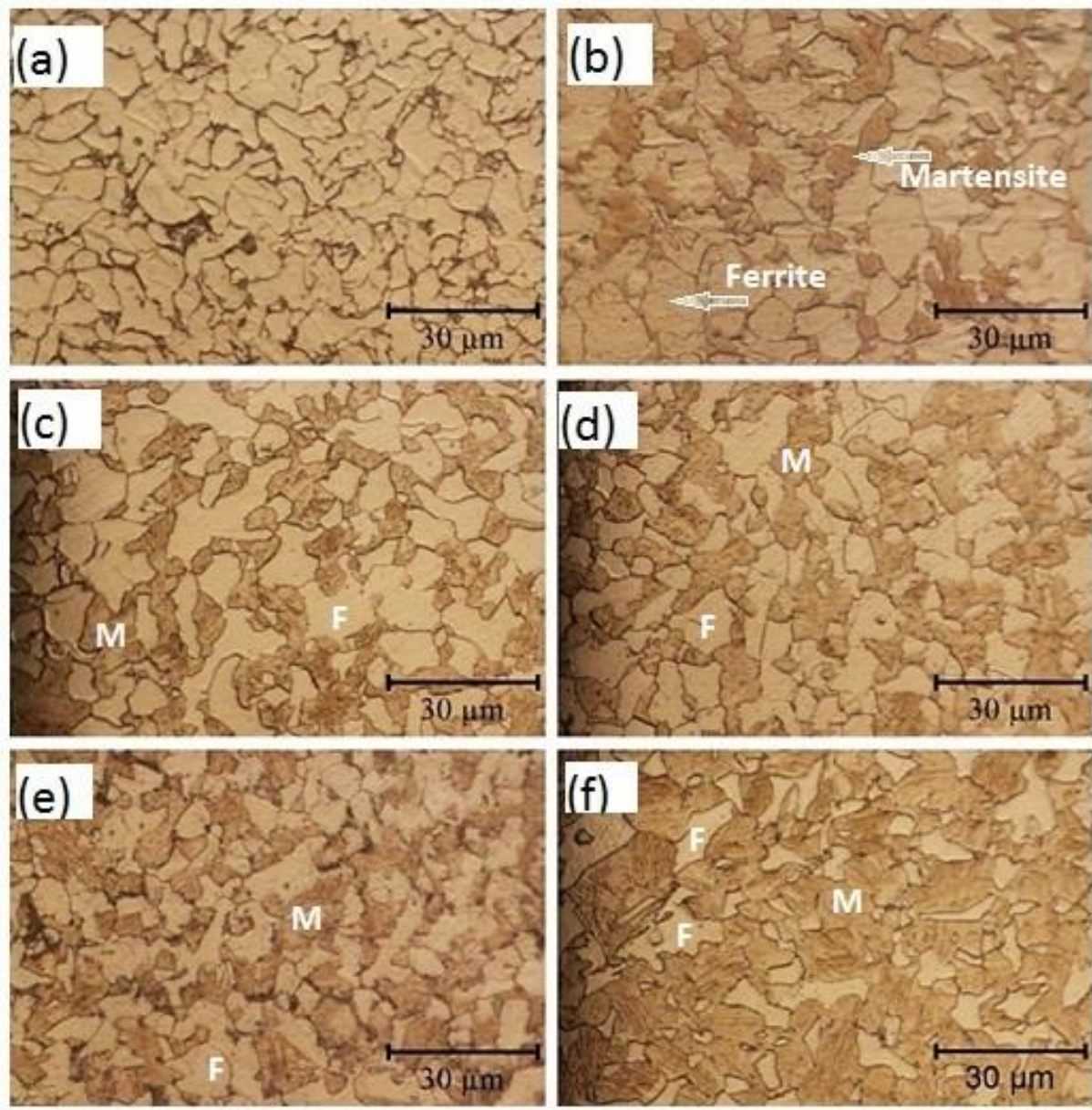

Fig. 1. Optical images of as-received (a), and heat-treated samples at: $760(b), 780(c)$, $800(d), 820(e)$ and $840{ }^{\circ} \mathrm{C}(f)$.

The effect of the heat treatment temperature on microhardness of ferrite and martensite phases is shown in Fig. 2. 


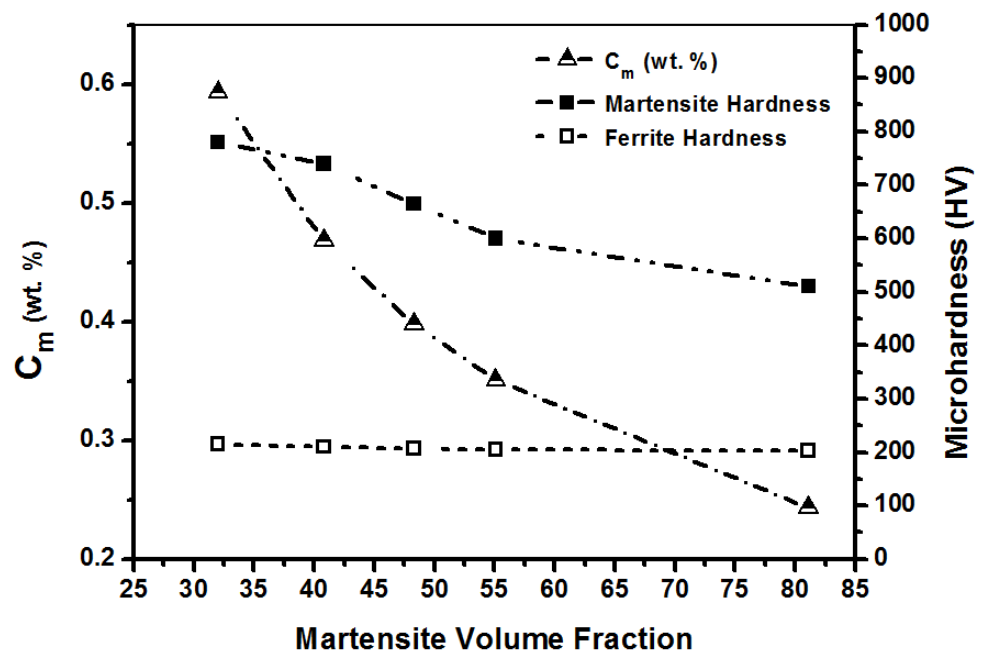

Fig. 2. Effect of heat treatment temperature on ferrite and martensite microhardness and carbon content of martensite.

As can be seen the microhardness of ferrite is nearly constant for all heat treatment temperature while the martensite microhardness is dependent to its volume fraction. Increase in the martensite volume fraction $\left(\mathrm{V}_{\mathrm{m}}\right)$ results to decreases in martensite microhardness.

In order to investigate the effect of heat treatment temperature on the tensile behavior, tensile tests were conducted on as-received and heat-treated samples. Fig. 3. represents the stress-strain curve for as-received and heat-treated samples at different intercritical temperatures. As shown in Fig. 3, yield point phenomenon is clearly visible in the stress-strain diagram of as-received sample, while all heat-treated samples show the typical behavior of as quenched DP steel with continuous yielding.
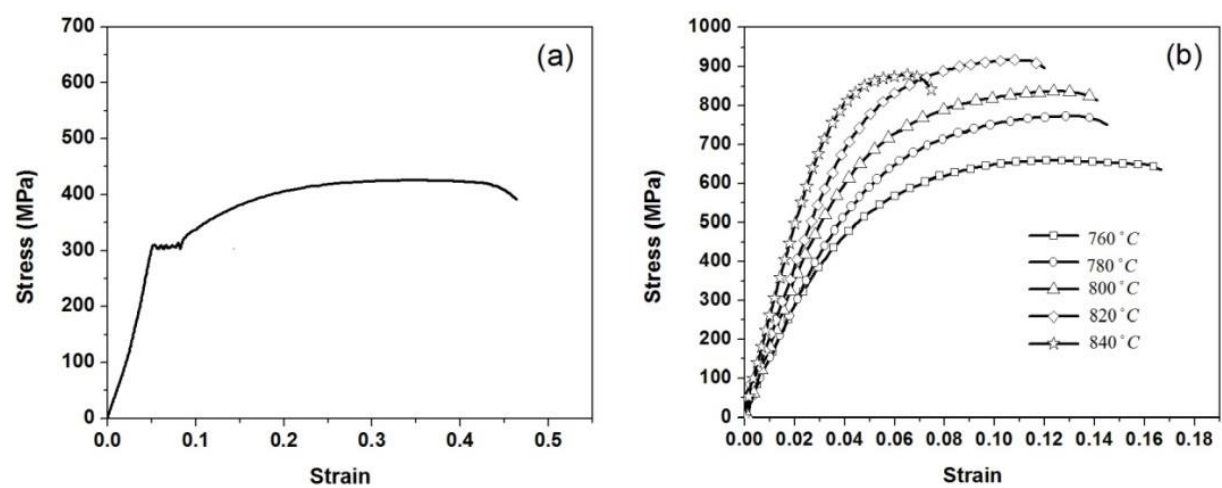

Fig. 3. Stress-strain curve of as- received (a), and heat-treated (b) samples.

The values of yield strength and ultimate strength ( $\sigma_{\mathrm{ys}}, \sigma_{\mathrm{uts}}$, respectively) for the as-received and heat-treated samples are presented in Table 2. The martensite volume 
fraction, carbon content of formed martensite, failure energy(FE), uniform $\left(\varepsilon_{\mathrm{u}}\right)$ elongations also are included.

Table 2. Mechanical specifications of the as received and heat-treated samples

\begin{tabular}{lcccccccc}
\hline Sample & $\begin{array}{c}\mathrm{HTT}^{*} \\
\left({ }^{\circ} \mathrm{C}\right)\end{array}$ & $\mathrm{V}_{\mathrm{m}}$ & $\begin{array}{c}\mathrm{C}_{\mathrm{m}} \\
(\mathrm{wt} . \%)\end{array}$ & $\begin{array}{c}\sigma_{\mathrm{ys}} \\
(\mathrm{MPa})\end{array}$ & $\begin{array}{c}\sigma_{\mathrm{uts}} \\
(\mathrm{MPa})\end{array}$ & $\begin{array}{c}\mathrm{FE} \\
(\mathrm{J})\end{array}$ & $\begin{array}{c}\varepsilon \mathrm{cu} \\
(\%)\end{array}$ & $\mathrm{n}$ \\
\hline As received & & & & 320 & 438 & & 36.35 & \\
A & $7 \overline{60}$ & 32 & 0.59 & 497 & 658 & 72 & 13.8 & 0.31 \\
B & 780 & 40.8 & 0.47 & 546 & 772 & 86 & 13.08 & 0.33 \\
C & 800 & 48.3 & 0.39 & 559 & 838 & 92 & 12.47 & 0.36 \\
D & 820 & 55.1 & 0.35 & 609 & 917 & 84 & 11.27 & 0.38 \\
& & & & & & & & $1^{\text {st }}$ stage: \\
E & 840 & 81.1 & 0.24 & 746 & 877 & 52 & 6.36 & $\begin{array}{c}0.43 \\
2^{\text {nd }} \text { stage: } \\
\end{array}$ \\
& & & & & & & 0.28 \\
\hline
\end{tabular}

"HTT: Heat Treatment Temperature

Fig. 4a represents the changes in yield strength $\left(\sigma_{y s}\right)$, ultimate strength $\left(\sigma_{u t s}\right)$ and failure energy for heat-treated samples in terms of the $V_{m}$. The results indicate that the yield strength in heat-treated samples (DP steels) increases by increment of $\mathrm{V}_{\mathrm{m}}$. However, the ultimate strength increases by increment of martensite at first and then decreases afterward. Maximum ultimate strength of heat-treated samples occurs at about $55 \% \mathrm{~V}_{\mathrm{m}}$. On the other hand, as shown in Fig. $4 \mathrm{a}$, the failure energy increases with increase in $\mathrm{V}_{\mathrm{m}}$ up to about $50 \%$ and decreases afterward.

The product of ultimate tensile strength $\left(\sigma_{\mathrm{uts}}\right)$ and uniform elongation $\left(\varepsilon_{\mathrm{u}}\right)$ at constant $\mathrm{V}_{\mathrm{m}}$ is usually used to evaluate the mechanical properties of the DP steels [18]. Utilizing this parameter could reveal the proper amount of $\mathrm{V}_{\mathrm{m}}$ to achieve the best combination of elongation and tensile strength of DP steels. Fig. 4b shows the product of $\sigma_{\mathrm{uts}}$ and $\varepsilon_{\mathrm{u}}$ at constant martensite volume fraction. As can be seen, increase in $\mathrm{V}_{\mathrm{m}}$ results to reduction in $\varepsilon_{\mathrm{u}}$. On the other hand, heat treatment between $780{ }^{\circ} \mathrm{C}$ and $800{ }^{\circ} \mathrm{C}$ causes the best combination of strength and elongation.
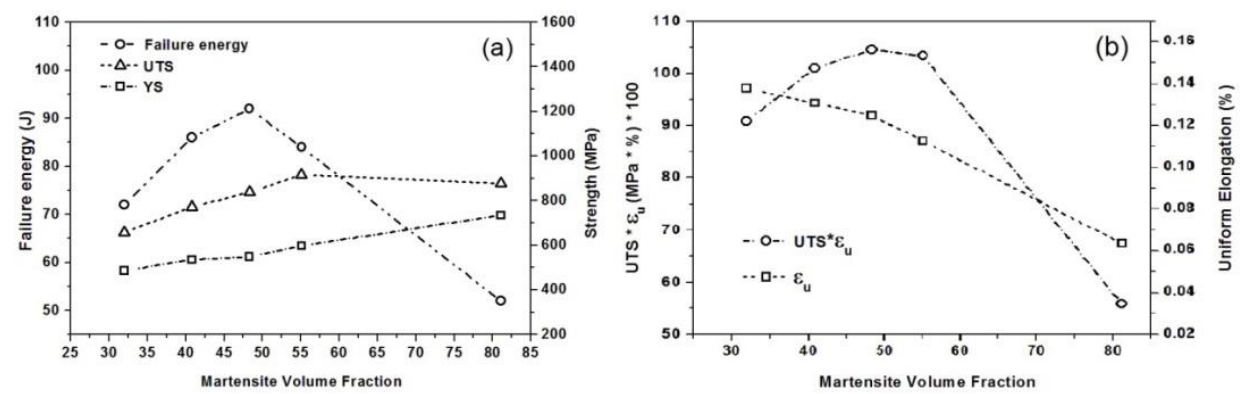

Fig. 4 Changes in yield strength, ultimate strength and failure energy (a) and product of tensile strength and uniform elongation (b) in terms of the martensite volume fraction. 
Work hardening behavior of most metals and alloys can be explained by Hollomon equation (Eq. 4) [19]:

$$
\sigma=K \varepsilon^{n}
$$

where, $\mathrm{K}$ is strength coefficient and $\mathrm{n}$ is work hardening exponent. $\mathrm{n}$ and $\mathrm{K}$ values are determined by plotting the stress-strain curve in logarithmic scale. Fig. 5 shows the $\ln \sigma-\ln \varepsilon$ graphs for heat-treated samples. As can be seen, in samples with less than $55 \% \mathrm{~V}_{\mathrm{m}}$, work-hardening behavior took place in single step, while at higher values of $\mathrm{V}_{\mathrm{m}}$ the results showed multistage behavior.

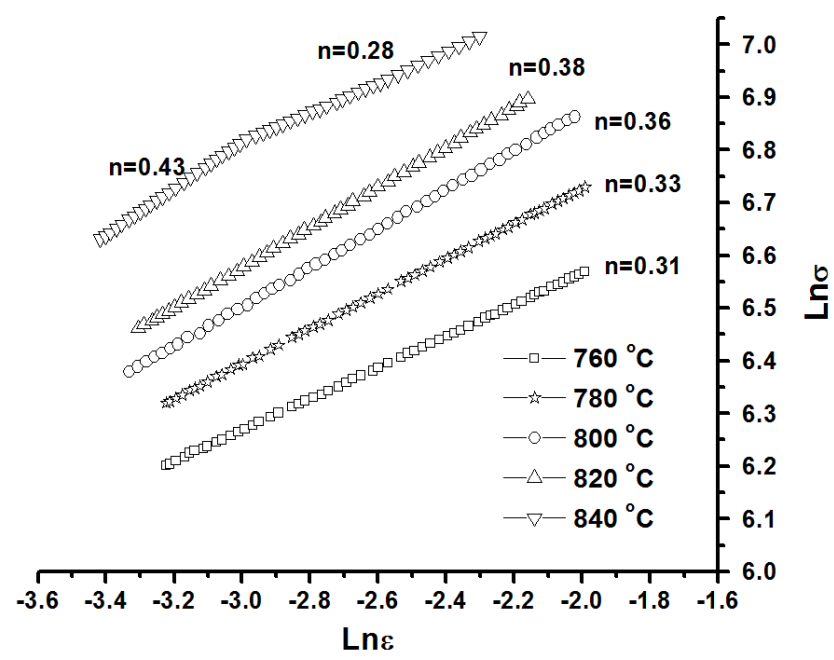

Fig. 5. Logarithmic graphs of true stress-strain curve for different heat-treated samples.

\section{Microstructural evaluation}

Higher $\mathrm{V}_{\mathrm{m}}$ in the microstructure with increase in the heat treatment temperature (Fig. 1) could be explained by the lever rule in the ferrite-austenite area. Increase in temperature of heat treatment in ferrite-austenite area results to a higher austenite fraction. Formed austenite transforms into martensite by quenching in water; therefore, the content of the martensite phase in heat-treated samples is increased by increment the austenite phase content due to increase in intercritical temperature. The obtained $\mathrm{V}_{\mathrm{m}}$ for all heat treatment temperature are summarized in Table2. Results showed that by increase in the heat treatment temperature to $840{ }^{\circ} \mathrm{C} \mathrm{V}$ increases up to $81 \%$ resulting to appearance of nearly continuous martensitic phase (Fig. 1d).

\section{Mechanical properties}

\section{Hardness measurement}

As shown in Fig. 2 the microhardness of the martensite is reduced by increase in the $\mathrm{V}_{\mathrm{m}}$, while the ferrite microhardness is nearly constant for all heat treatment temperatures. It is worth noting that the hardness of ferrite and martensite are in direct relationship with their carbon content [3]. The constant microhardness of the ferrite could be related to the solubility limit of the carbon in the ferrite $(0.015 \mathrm{wt}$. \%). On the other hand, the carbon content of martensitic phase can be estimated by Equation 5 [20]. 
$C_{m}=\left(C_{0}-C_{f}\left(1-V_{m}\right)\right) / V_{m}$

where: $\mathrm{C}_{0}$ is the mean carbon content of as-received steel, $\mathrm{C}_{\mathrm{f}}$ and $\mathrm{C}_{\mathrm{m}}$ are carbon content in ferrite and martensite phases, respectively, and $\mathrm{V}_{\mathrm{m}}$ is the volume fraction of martensite phase. If assumed that the ferrite is supersaturated in carbon, i.e. 0.015, the carbon content of martensitic phase will be obtained utilizing Equation 5. As it can be observed the carbon content of the martensite decreases by increasing the $V_{m}$ (Fig. 2) and consequently the martensite microhardness shows the descending trend by $\mathrm{V}_{\mathrm{m}}$ increasing.

\section{Tensile properties}

As shown in Fig. 3a, the yield point phenomenon is clearly observable in stressstrain curve of as-received sample. Discontinuous yielding in low carbon steels is due to effect of interstitial carbon atoms on locking dislocations. The needed stresses to mobilize dislocations is less than the needed stress to release the locked dislocations; therefore, in tensile test, the stress level increased initially because of locked dislocations, but stress will have to decrease due to their movement, which leads to creation of the upper and lower limits of the yield stress on the stress-strain curve. In general, various factors such as low density of mobile dislocations before deformation, rapid multiplication of dislocations during deformation and considerable dependence of the speed of the dislocations movement on applied stress influence on creating yield phenomena [1,3].On the other hand, the transformation of austenite to martensite in ferritic matrix in DP ferritic-martensitic steels leads to plastic deformation in adjacent ferrite matrix and consequently production of new mobile dislocations in adjacent ferrite-martensite interface. Transmission electron microscopy studies have shown that high density of dislocations is present in ferrite areas adjacent to the martensite particles in the dual-phase steels [21]. The continuous yield of DP steels should be considered as a result of the presence of a large number of mobile dislocations in their microstructures [22].

As shown in Fig. 4a, the strength and failure energies of heat treated samples depend on $\mathrm{V}_{\mathrm{m}}$. It is worth noting that the DP steel strength relates to various parameters such as $\mathrm{V}_{\mathrm{m}}$ and strength of formed martensite [3]. Up to $55 \% \mathrm{~V}_{\mathrm{m}}$, DP steel strength is increased by increasing of $\mathrm{V}_{\mathrm{m}}$ due to increase in amount of hard martensite phase. On the other side, the strength of martensite phase is related to the carbon content and is reduced by decreasing the carbon content [3]. The reduction in strength of martensite with increasing the $V_{m}$ because of lower carbon content in martensite (Fig. 2) will cause to decrease of the ultimate strength in DP steels at $\mathrm{V}_{\mathrm{m}}$ higher than 55\%.

The variation of failure energies of the heat-treated samples by increase in the $V_{m}$ results from confrontation of two parameters: formation of compressive stresses in the structure because of austenite to martensite transformation and appearance of continuous martensite phase due to increase of its volume fraction. Austenite to martensite transformation is associated with volume expansion of about $4 \%$, therefore, compressive stress is created in the structure. These compressive stresses at the interface between ferrite and martensite phase will hinder crack growth if crack initiation occurs [23] and this will lead to increase in failure energy. On the other hand, metallographic observations (Fig. 1) show that soft ferrite matrix loses its continuity with increase of 
$\mathrm{V}_{\mathrm{m}}$. Thus, structure becomes brittle with increase of $\mathrm{V}_{\mathrm{m}}$ and consequently failure energy is reduced.

The work hardening values of all DP steels obtained from different heat treatment temperature are summarized in Table 2. The work hardening exponent increases with increase in $\mathrm{V}_{\mathrm{m}}$. It should be noted that, the work hardening exponent is a measure of softness then it is expected that the work hardening exponent decreases by increase in $\mathrm{V}_{\mathrm{m}}$. This complex behavior could be explained by changes in the strength of ferrite and martensite connected with increase of $\mathrm{V}_{\mathrm{m}}$. As already mentioned the strength of martensite is reduced with increase of $V_{m}$ due to reduction of carbon content in martensite. This leads to a decrease of hardness of martensite phase resulting in increase of work hardening exponent with increase in heat treatment temperature. As indicated in Fig. 5, the work hardening behavior of the sample with $81 \% \mathrm{~V}_{\mathrm{m}}$ takes place in two stages. In multistage work hardening behavior, the first stage is related to plastic deformation of ferrite network which has high work hardening exponent, while the second stage is related to simultaneous plastic deformation of ferrite and martensite phase which work hardening exponent is reduced at this step [3, 24].

\section{Conclusion}

The obtained results in this study could be summarized as follows:

1. The volume fraction of martensite phase is increased by increment the critical heat treatment temperature and according to the rule of mixtures the weight percent of carbon of created martensite phase is decreased.

2. Yield strength of dual-phase steel is increased by increment of volume fraction of martensite phase.

3. Ultimate strength is increased by increment of the volume fraction of martensite phase up to $55 \%$ but was decreased with formation of higher martensite volume fraction.

4. The work-hardening behavior of samples with values less than $55 \%$ of martensite volume fraction is a single step process and work hardening exponent is increased with increase in volume fraction of martensite.

5. The work-hardening behavior of samples with values higher than $55 \%$ of martensite volume fraction is a two-step deformation process indicating that dual-phase steel has a complex deformation behavior in the case of high martensite volume fraction.

\section{References}

[1] M. Calcagnotto, Y. Adachi, D. Ponge, D. Raabe, Acta Mater, 59 (2011) 658-670.

[2] R. J. Pallett, R. J. Lark: J Mater Pro Tech, 117 (2001) 249-254.

[3] P. Movahed, S. Kolahgar, S.P.H. Marashi, M. Pouranvari, N. Parvin: Mater Sci Eng A, 518 (2009) 1-6.

[4] Y. Mazaheri, A. Kermanpur, A. Najafizadeh: Mater Sci Eng A, 619 (2014) 1-11.

[5] M. Calcagnotto, D. Pong, D. Raabe: Mater Sci Eng A, 527 (2010) 7832-7840.

[6] N. Peranio, Y.I. Li, F. Roters, D. Rabbe: Mater Sci Eng A, 527 (2010) 4161-4168.

[7] C. Zheng, D. Rabbe: Acta Mater, 61 (2013) 5504-5517.

[8] L. Shi, Z. Yan, Y. Liu, C. Zhang, Z. Qiao, B. Ning, H. Li: Mater Sci Eng A, 590 (2014) 7-15. 
[9] V. Colla, M. De Sanctis, A. Dimatteo, G. Lovicu, A. Solina, R. Valentini: Metall Mater Trans A, 40A, (2009) 2557-2567.

[10] X. Cai, C. Liu, Z. Liu: Mater and Des, 53 (2014) 998-1004.

[11] V. H. Baltazar Hernandez, S.S. Nayak, Y. Zhan: Metals and Materials Society, 42A (2011) 3115-3129.

[12] E. Ahmad, T. Manzoor, N. Hussain: Mater Sci Eng A, 508 (2009) 259-265.

[13] A. Fallahi: J Mater Sci Tech, 18 (2002) 451-456.

[14] A. Bag, K. Ray, ES. Dwarakadasa, Metall Mater Trans A, 30 (1999) 1193-1196.

[15] H.C. Chen, G.H. Cheng: J Mater Sci, 24 (1989) 1991-1995.

[16] M. A. Maleque, Y. M. Poon, H. H. Masjuki: J Mater Pro Tech, 152-154 (2004) 482-487.

[17] R. Silverman, Modern Calculus and Analytic Geometry, Macmillan Company, 2003.

[18] A. Anazadeh Sayed, Sh. Kheirandish: Mater Sci Eng A, 532 (2012) 21-25.

[19] J. H. Hollomon: Trans AIME, 162 (1945) 268-290.

[20] M. Delinc, Y. Brechet, J.D. embury, M.G.D. Geers, P.J. Jacques, T. Pardoen: Acta Mater, 55 (2007) 2337-2350.

[21] D. A. Korzekwa, D. K. Matlock, G. Krauss: Metall Trans A 15 (1984) 1221-1228.

[22] S. S. Hasen, R. R. Pradhan: TME-AIME, 23 (1981) 113-144.

[23] H. Saghafian, Sh. Kheirandish: Mater Lett 61 (2007) 3059-3064.

[24] J. Zhang, H. Di, Y. Deng, R. D. K. Misra: Mater Sci Eng A, 627 (2015) 230-240. 